Supplement of Biogeosciences, 17, 441-454, 2020

https://doi.org/10.5194/bg-17-441-2020-supplement

(C) Author(s) 2020. This work is distributed under

the Creative Commons Attribution 4.0 License.

(c) (1)

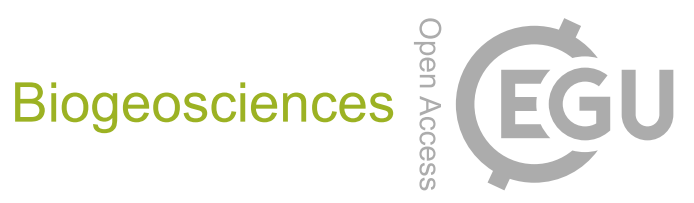

Supplement of

\title{
Estimates of mean residence times of phosphorus in commonly considered inorganic soil phosphorus pools
}

\section{Julian Helfenstein et al.}

Correspondence to: Julian Helfenstein (julian.helfenstein@ agroscope.admin.ch) and Chiara Pistocchi (chiara.pistocchi@ supagro.fr)

The copyright of individual parts of the supplement might differ from the CC BY 4.0 License. 


\section{Supplementary figures}

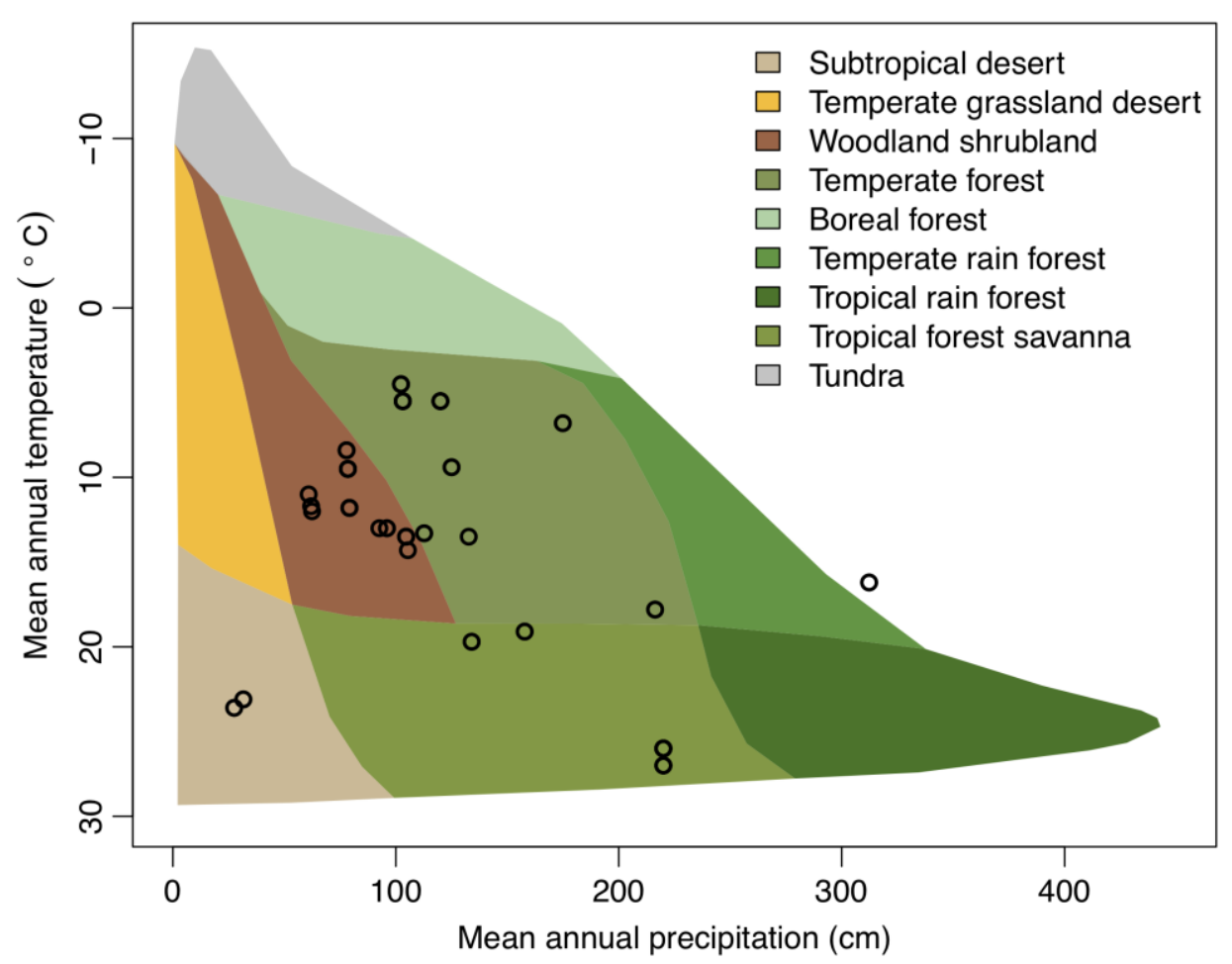

Figure S1. Whittaker's diagram showing the main biomes covered by our dataset based on mean annual temperature and mean annual precipitation. 


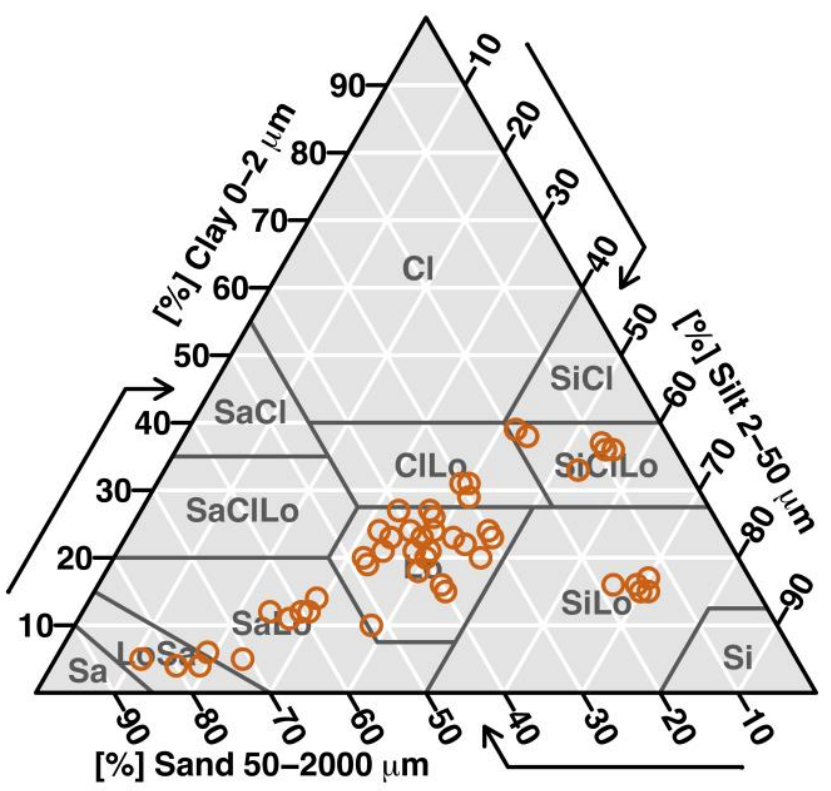

Figure S2. Soil texture triangle to determine the soil texture classes comprised in our dataset.

a)

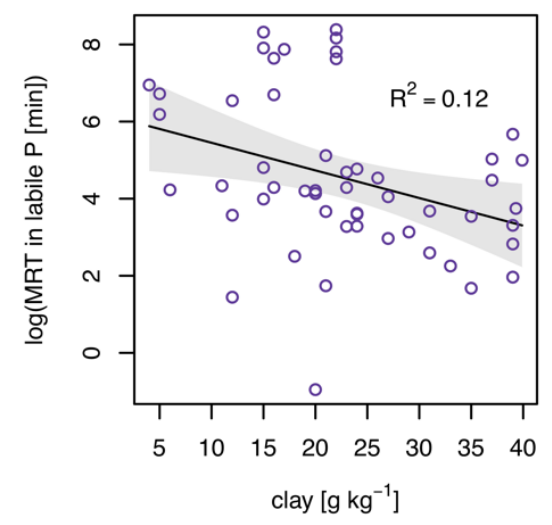

b)

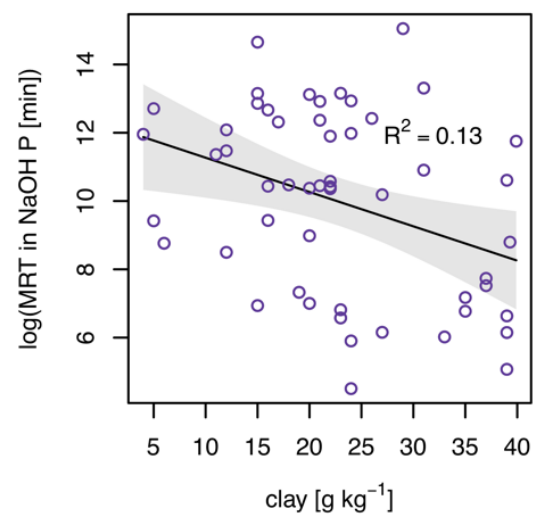

c)

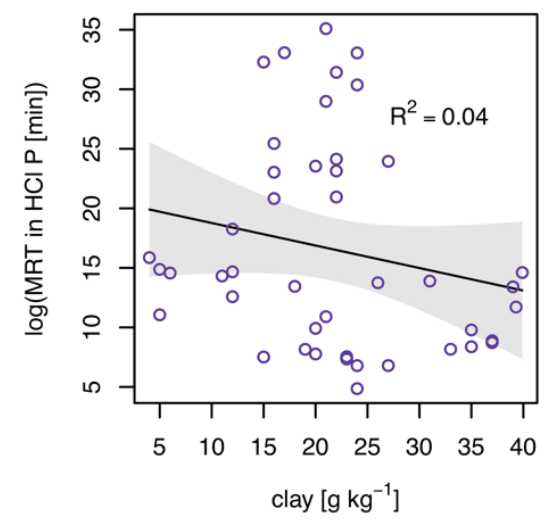

Figure S3. Simple regression of calculated mean residence time of $P$ with clay concentration. The model was significant for labile $P$ $(F$-statistic $=6.8, p=0.01)$ and NaOH-P $(F$-statistic $=7.1, p<0.01)$, but not for HCP $(F$-statistic $=1.8, p=0.18)$. 


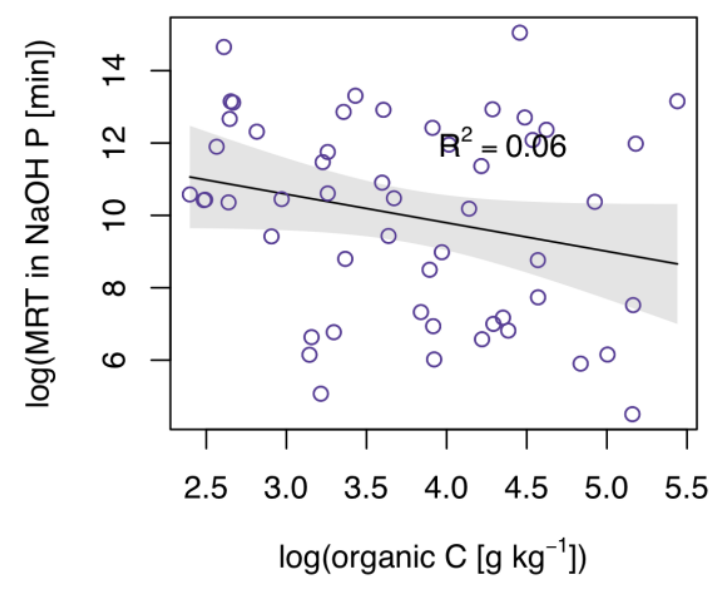

Figure S4. Simple regression of calculated mean residence time of $\mathrm{P}$ in $\mathrm{NaOH}-\mathrm{P}$ with organic $\mathrm{C}$. The model was not significant $(F$-statistic $=3.2, p=0.08)$. 

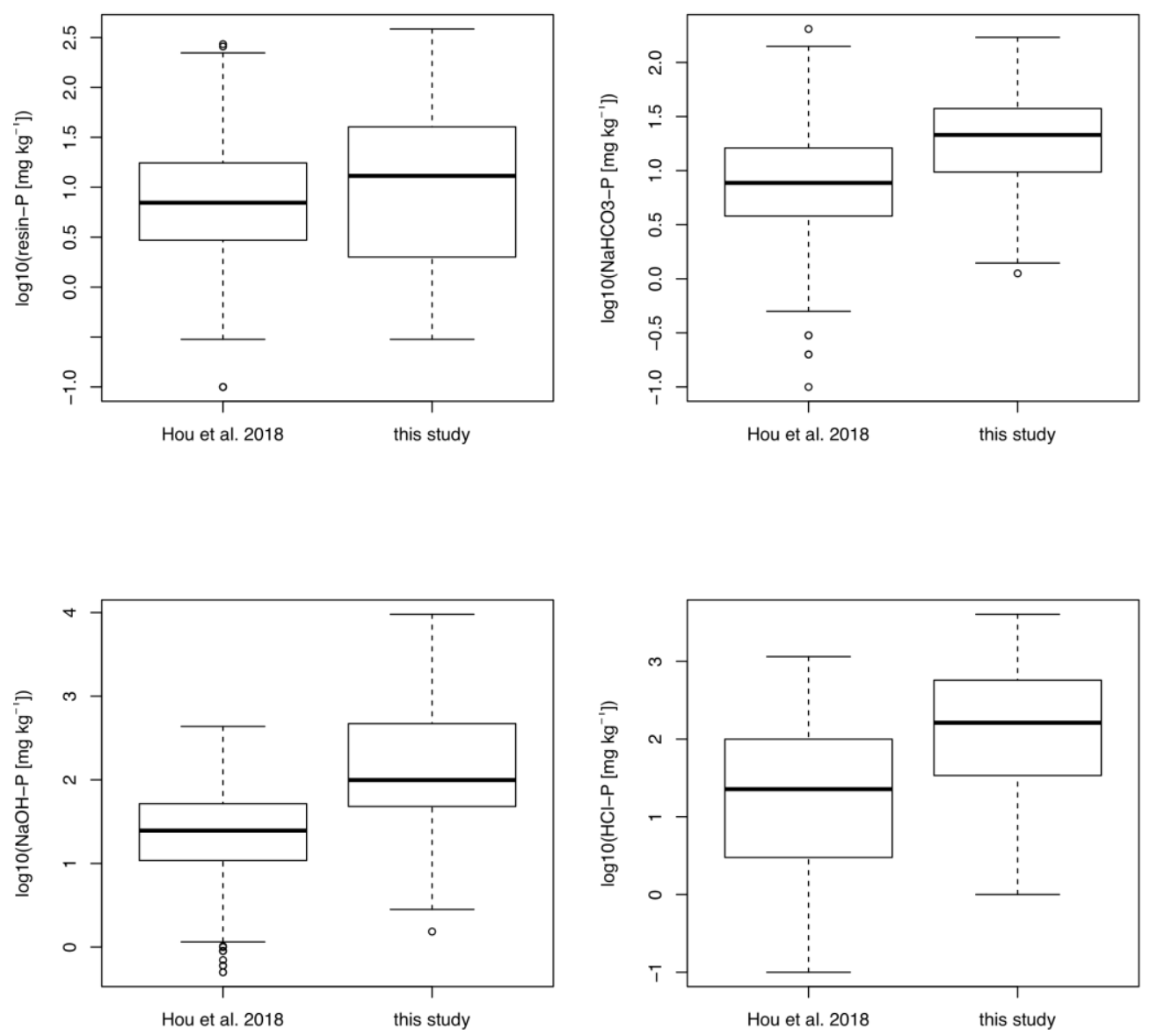

Figure S5. Comparison of soil $P$ pools in this study $(n=57)$ and in a larger dataset $(n=802)($ Hou et al., 2018). 

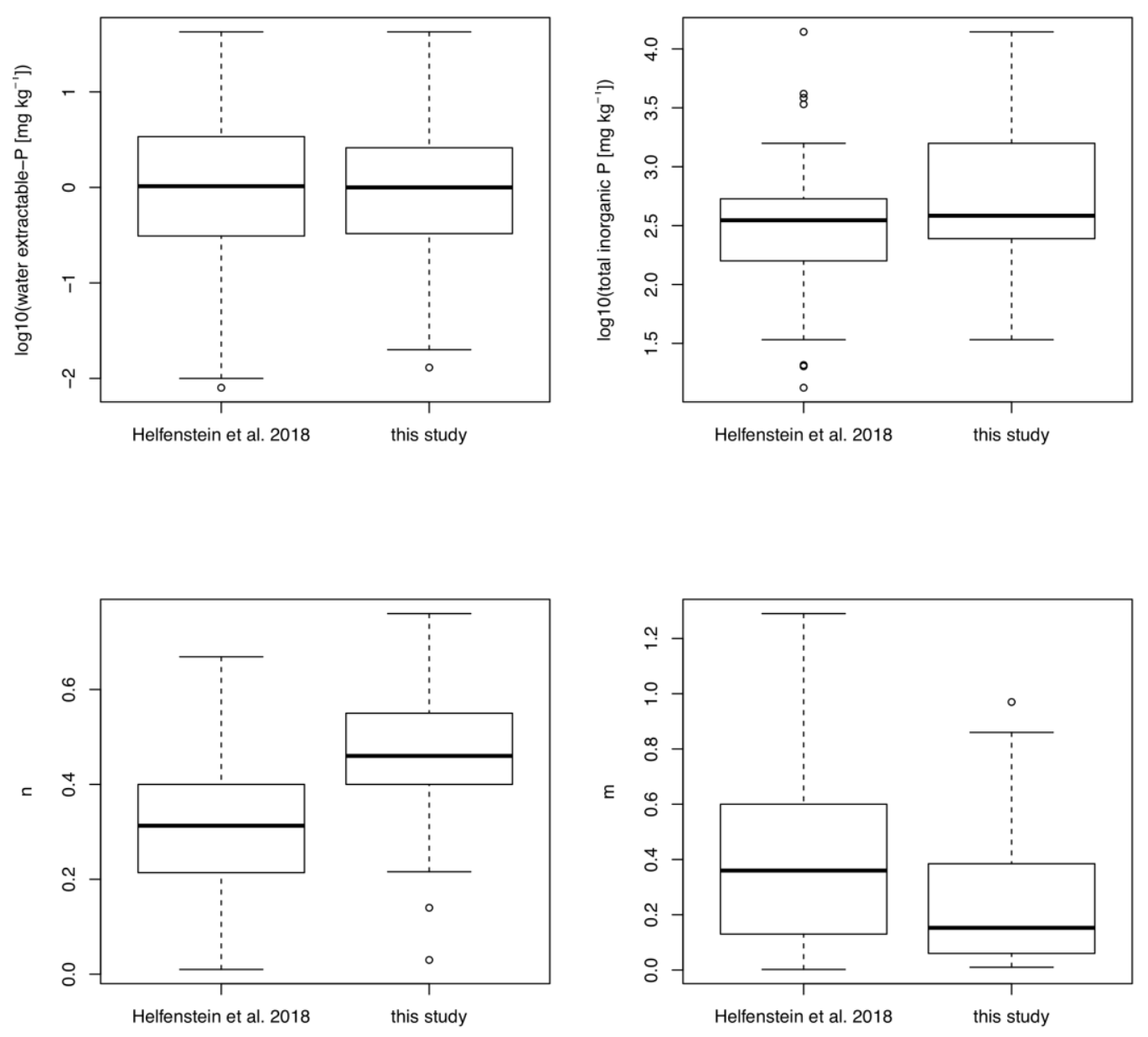

Figure S6. Isotope exchange kinetic properties of this study $(n=57)$ in comparision to a larger dataset $(n=217)($ Helfenstein et al., 2018b). 
Table S1. Sources for data on soil and other properties for each site.

\begin{tabular}{ccccccccc}
\hline Study code & IEK & $\begin{array}{c}\text { sequential. } \\
\text { extraction }\end{array}$ & pH & soil texture & organic C & MAT & MAP & parent \\
laterial
\end{tabular}

